\title{
Article \\ Silver Inkjet-Printed Electrode on Paper for Electrochemical Sensing of Paraquat
}

\author{
Patricia Batista Deroco (D), Dagwin Wachholz Junior (D) and Lauro Tatsuo Kubota * \\ Institute of Chemistry, University of Campinas_UNICAMP, 13083-970 Campinas, Brazil; \\ patyderoco@hotmail.com (P.B.D.); dagwinjr@gmail.com (D.W.J.) \\ * Correspondence: kubota@unicamp.com; Tel.: +55-19-3521-3127
}

Citation: Deroco, P.B.; Wachholz Junior, D.; Kubota, L.T. Silver Inkjet-Printed Electrode on Paper for Electrochemical Sensing of Paraquat. Chemosensors 2021, 9, 61. https:// doi.org/10.3390/chemosensors 9040061

Academic Editor: Emilia Witkowska Nery

Received: 1 March 2021

Accepted: 22 March 2021

Published: 25 March 2021

Publisher's Note: MDPI stays neutral with regard to jurisdictional claims in published maps and institutional affiliations.

Copyright: (c) 2021 by the authors. Licensee MDPI, Basel, Switzerland. This article is an open access article distributed under the terms and conditions of the Creative Commons Attribution (CC BY) license (https:// creativecommons.org/licenses/by/ $4.0 /)$.

\begin{abstract}
The use of fully printed electrochemical devices has gained more attention for the monitoring of clinical, food, and environmental analytes due to their low cost, great reproducibility, and versatility characteristics, serving as an important technology for commercial application. Therefore, a paper-based inkjet-printed electrochemical system is proposed as a cost-effective analytical detection tool for paraquat. Chromatographic paper was used as the printing substrate due its sustainable and disposable characteristics, and an inkjet-printing system deposited the conductive silver ink with no further modification on the paper surface, providing a three-electrode system. The printed electrodes were characterized with scanning electron microscopy, cyclic voltammetry, and chronopotentiometry. The proposed sensor exhibited a large surface area, providing a powerful tool for paraquat detection due to its higher analytical signal. For the detection of paraquat, square-wave voltammetry was used, and the results showed a linear response range of 3.0-100 $\mu \mathrm{M}$ and a detection limit of $0.80 \mu \mathrm{M}$, along with the high repeatability and disposability of the sensor. The prepared sensors were also sufficiently selective against interference, and high accuracy (recovery range = 96.7-113\%) was obtained when applied to samples (water, human serum, and orange juice), showing the promising applicability of fully printed electrodes for electrochemical monitoring.
\end{abstract}

Keywords: printed electronics; electroanalysis; disposable electrode; chromatographic paper; paraquat determination; silver ink; inkjet printing

\section{Introduction}

The development of fully printed analytical devices has been increasingly active in the market of printed electronics. It is estimated that, in 2020, the market reached around $\$ 7.8$ billion, and it is expected to increase to $\$ 20.7$ billion by 2025 [1]. This growth is due to the use of analytical devices for real-time detection in clinical, food, and environmental applications, which are crucial technologies for improving well-being and life quality. Especially in low- and middle-income countries, many people suffer unnecessarily due to the lack of access to these technologies at affordable prices. Printed electrochemical sensors represent an important cost-effective analytical detection technology for disposable and one-shot use sensors, which are a powerful and extremely necessary tool to fill this gap [2]. Moreover, the ability to achieve highly sensitive analytical detection without the requirement of further modification to printed electrochemical sensors gives them high potential for industrial production and commercialization, where minimal costs and ease of production are essential [3].

With the evolution of microelectronics and the possibility of automatization, electrochemical sensors have become more available, demonstrating reliable performance for the detection of important analytes and applicability in the real world. Thus, the development of disposable printed electrodes is gaining importance globally, and many notable works have been reported in the literature [4-6]. In the search for low-cost devices, the application of paper as a substrate for printed electrodes has attracted great attention recently due to 
the abundance of the material, and they are a more sustainable and disposable alternative to conventional materials, such as glass or polymers [7-9]. Additionally, interesting designs of devices with paper substrates can be realized to allow the simultaneous measurement (detection) of several analytes from a single sample with the combination of different detection techniques. Due to its versatility, paper allows the construction of innovative devices with the integration of several analytical procedures, such as reagent pre-location, chromatographic separations, pre-concentration steps, integration of sample pre-treatment systems, and so on [10,11].

Among the various techniques for the deposition of conductive materials on paper, screen- and inkjet-printing technologies are the most attractive because these processes are versatile, low-cost, and suitable for miniaturization and large-scale production $[9,12]$. Particularly, inkjet printing is a deposition technology that digitally controls small ejected drops (in the picoliter-nanoliter range) of ink in specific locations on the substrate in a fully automated manner, which allows high precision and resolution with great reproducibility of the printed electrodes [13]. Moreover, the great advantage of inkjet printing over screen printing is that no mask is required. Specific patterns, according to users' needs, can be projected on the computer using common graphic drawing software and sent directly to the printer $[14,15]$. Although commercial ink formulations are available, there are also countless possibilities for the development of conductive inks containing functional materials, such as biomolecules and nanomaterials [16-18].

Despite their advantages, there are still few reports of the use of the inkjet-printing technique to manufacture electrochemical sensors when compared to those using the screen-printing technique. For these reasons, we report the development of a fully printed electrochemical device based on chromatographic paper using an inkjet-printing technique with conductive silver ink and without further modification in order to explore the suitability of the material and technique for use in electrochemical detection.

In this work, the pesticide paraquat was chosen as a representative molecule for performance evaluation of the printed electrode. Paraquat is one of the most toxic substances and widely used in agriculture in more than 100 countries [19]. Although it is only slightly adsorbed by the soil, paraquat is a potential contaminant of water due to its high solubility, becoming potentially dangerous for aquatic systems and consequently for human and animal health [20]. Since paraquat is considered a non-polluting herbicide, it is often used indiscriminately, increasing its toxicological potential and the risk posed to human health. Consequently, many studies have demonstrated the detection of paraquat using different electrodes, such as modified glassy carbon electrodes [21-26], hanging mercury drop electrodes [27], and screen-printed electrodes [28,29]. These reported devices, however, suffer from high material and manufacturing costs, have poor disposability, are not suitable for portable detection, and involve complex electrode modification steps in some cases.

Therefore, the purpose of using a paper-based silver electrode deposited by the inkjetprinting method is to meet requirements for high performance, low-cost, and disposability; eliminate the so-called memory effect caused by surface contamination; and provide an efficient tool for the simple and cost-effective monitoring of intended analytes.

\section{Materials and Methods}

\subsection{Reagents and Standards}

The standards of paraquat dichloride (methyl viologen), potassium ferricyanide $\mathrm{K}_{3}\left[\mathrm{Fe}(\mathrm{CN})_{6}\right]$, and hexaammineruthenium(III) chloride $\left[\mathrm{Ru}\left(\mathrm{NH}_{3}\right)_{6}\right] \mathrm{Cl}_{3}$ were purchased from Sigma-Aldrich, while $\mathrm{Na}_{2} \mathrm{SO}_{4}$ was purchased from Merck and used without further purification. All other reagents were of analytical grade, and all solutions were prepared in ultrapure water ( $\rho \geq 18.2 \mathrm{M} \Omega \mathrm{cm}$ ) obtained using a Milli-Q system. A $0.01 \mathrm{~mol} \mathrm{~L}^{-1}$ stock solution of paraquat was prepared daily in a $0.1 \mathrm{~mol} \mathrm{~L}^{-1} \mathrm{Na}_{2} \mathrm{SO}_{4}$ aqueous solution, which was also used as the supporting electrolyte.

Silver nanoparticle (AgNP) ink for the inkjet printer $(<50 \mathrm{~nm}, 20 \mathrm{wt} . \%$ in ethylene glycol) and the substrate Whatman\# $1^{\circledR}$ chromatographic paper were also purchased from 
Sigma-Aldrich. A commercial bleach solution (approximately $40 \mathrm{mg} \mathrm{mL}^{-1} \mathrm{NaClO}$ ) was used to modify the silver surface to obtain a pseudo-reference electrode $(\mathrm{Ag} / \mathrm{AgCl})$.

A sample of orange fruit was purchased from a local supermarket. First, the juice of five oranges was manually extracted, homogenized, and centrifugated, and the supernatant was used for the analysis. Tap water samples were collected at the University of Campinas (São Paulo, Brazil) and used without any treatment. Human serum (male, AB, filtered, and sterile) was purchased from Sigma-Aldrich (St. Louis, MO, USA) and centrifugated, and the supernatant was used for the analyses.

Before the analyses, all samples were spiked with paraquat. Then, aliquots of $200 \mu \mathrm{g} / \mathrm{L}$ of each sample were diluted in the supporting electrolyte solution, and final solutions with a concentration of $30 \mu \mathrm{mol} \mathrm{L}{ }^{-1}$ paraquat were analyzed.

\subsection{Apparatus}

A piezoelectric Dimatix Materials Printer DMP-2831, FUJIFILM Dimatix, Inc., Santa Clara, CA, USA, was used to print the AgNP ink on the paper substrate.

The electrochemical measurements were performed using an AUTOLAB PGSTAT-30 potentiostat/galvanostat (Metrohm/Eco Chemie, Utrecht, The Netherlands) interfaced with a computer and managed by NOVA 2.1 software (Metrohm/Eco Chemie, Utrecht, The Netherlands).

To evaluate the performance of the proposed inkjet-printed pseudo-reference electrode, a two-electrode system was used with a commercial $\mathrm{Ag} / \mathrm{AgCl}$ (saturated $\mathrm{KCl}$ solution) reference electrode (Methrom/Eco Chemie, Utrecht, Netherlands). A conventional threeelectrode system was also used, including a Pt wire as the auxiliary electrode, glassy carbon as the working electrode, and the proposed pseudo-reference electrode.

A field-emission scanning electron microscope (SEM), model JEOL J6360 LV (JEOL Ltd., Tokyo, Japan) operating at a voltage of $20 \mathrm{kV}$, was used to morphologically characterize the silver film on paper.

An Eppendorf centrifuge (model 5418 R) (Eppendorf Zentrifugen GmbH, Leipzig, Germany) with a speed capacity of 100-14,000 rpm was used to centrifuge the samples.

An optical microscope (AmScope B120C) equipped with a Fixed Microscope Adapter (FMA050) (AmScope, Irvine, CA, USA) was used to obtain images and determine the geometrical area of the printed electrode. The images were processed with Adobe Photoshop ${ }^{\circledR}$ CC 2019 Software, Adobe, San Jose, CA, USA, in order to normalize the areas, considering a standard pattern in the same amplification of the microscope. The areas of 15 different electrodes were determined to get the average value and evaluate the repeatability.

\subsection{Paper-Based Inkjet Sensor Printing}

First, $1.5 \mathrm{~mL}$ of the AgNP ink was injected into a $10 \mathrm{pL}$ DMC-116110 cartridge. Then, a three-electrode system was designed using CorelDraw ${ }^{\circledR}$ software, Corel, Ottawa, Canada and printed on chromatographic paper using the inkjet Dimatix Printer, FUJIFILM Dimatix, Inc., Santa Clara, CA, USA. The waveform used to print was "Dimatix Model Fluid 2 Waveform" with a voltage between 16 and $20 \mathrm{~V}$. The printing process was carried out at room temperature, and cleaning cycles (Purge $1.0 \mathrm{~s}$ Blot) were used only before printing. A spacing of $30 \mu \mathrm{m}$ between two consecutive drops and 4 layers of ink were necessary to obtain a conductive silver film on chromatographic paper. After each layer, the silver ink was cured at $120^{\circ} \mathrm{C}$ for $20 \mathrm{~min}$.

Next, a specific hydrophobic pattern barrier was printed on paper using a ColorQube 8570 office printer from Xeroxand employing cartridge-free ColorQube solid ink-Xerox 108R00940 (Xerox Corporation Norwalk, CT, USA). The wax-printed sheet was kept in an oven for $1 \mathrm{~min}$ at $100^{\circ} \mathrm{C}$ in order to melt the wax and create a hydrophobic wall due to its penetration into the porous paper.

The geometric area of the working electrode was determined using microscope images, and a value of $0.080 \pm 0.001 \mathrm{~cm}^{2}(n=15, \mathrm{RSD}=1.61 \%)$ was obtained. This new sensor was referred to as the paper-based silver sensor. 
The pseudo-reference electrode was prepared using a procedure developed by Silva et al. [30]. The $\mathrm{Ag} / \mathrm{AgCl}$ formation was carried out by depositing a drop of bleach solution just on top of the pseudo-reference electrode for $30 \mathrm{~s}$, which was then rinsed with ultrapure water. The obtained pseudo-reference electrode was then used without any further modification.

\subsection{Electrochemical Measurements}

Chronopotentiometric measurements were employed to characterize the electrochemical activity of the $\mathrm{Ag} / \mathrm{AgCl}$ pseudo-reference electrode against a commercial $\mathrm{Ag} / \mathrm{AgCl}$ reference electrode. These measurements of open circuit potential were carried out in saturated $\mathrm{KCl}$ solution for $15 \mathrm{~min}$.

The paraquat electrochemical behavior was investigated using cyclic voltammetry $(\mathrm{CV})$, whereas the determination of this analyte was performed using square-wave voltammetry (SWV). The SWV conditions used were $f=3 \mathrm{~Hz} ; a=60 \mathrm{mV} ; \Delta E=2 \mathrm{mV}$.

All measurements were performed in triplicate $(n=3)$ using three different disposable electrodes by simply dropping $50 \mu \mathrm{L}$ of the sample on the sensor testing area.

The limits of detection (LOD) and quantification (LOQ) were calculated using the equation $3(\mathrm{Sy} / \mathrm{b})$ and $10(\mathrm{Sy} / \mathrm{b})$, respectively, where Sy is the standard deviation of the intercept and $b$ the slope of the analytical curve [31].

\section{Results}

\subsection{Morphological and Electrochemical Characterization of Inkjet-Printed Sensors}

First, the effect of the number of printed silver nanoparticles layers on the paper substrate was investigated to optimize the conductivity of the inkjet-printed electrode. After each printing step, the resistance of the printed layer was measured in order to achieve the lowest value. It was observed that the resistance of the printed electrode decreased, and the current signal for the silver cyclic voltammetric profile was enhanced as the number of printed layers increased (Figure S1). After four layers of silver ink deposition, a constant and lower resistance value and high current signal were achieved. Therefore, this condition was chosen for the printing step of the electrode.

The images obtained from scanning electron microscopy (SEM) before (Figure 1A) and after the printing of silver ink (Figure 1B,C) show that with the inkjet-printing process, the paper fibers were clearly modified and totally surrounded by silver nanoparticles of approximately $50 \mathrm{~nm}$ (Figure 1C). The SEM and optical images (Figure 1D) also show the high porosity of the paper substrate, indicating a large surface area of the electrode. The roughness of the electrode border seen in Figure 1D can be attributed to the porosity of the paper, which allows the silver ink to percolate into the pores of the substrate, which may increase the electroactive area of the electrode.

The performance of the inkjet-printed solid-state $\mathrm{Ag} / \mathrm{AgCl}$ pseudo-reference electrode was evaluated by chronopotentiometry in saturated $\mathrm{KCl}$ against a commercial $\mathrm{Ag} / \mathrm{AgCl}$ (saturated $\mathrm{KCl}$ solution) reference electrode (Figure 2A). As can be observed, there is no significant difference between these electrodes (open circuit potential value measured of $0.3 \pm 0.1 \mathrm{mV}$ ), which highlights the stability of the proposed pseudo-reference electrode. As reported by Silva et al. [30], this small deviation from the ideal value of zero may be attributed to slight differences in the chloride activity in the test solution and the commercial reference filling solution or to an uncertain junction potential. The reliability of the proposed pseudo-reference was also confirmed by cyclic voltammograms obtained for the glassy carbon electrode using the pseudo-reference electrode (duplicate) or commercial $\mathrm{Ag} / \mathrm{AgCl}$ in the presence of $1.0 \mathrm{mmol} \mathrm{L}^{-1} \mathrm{~K}_{3}\left[\mathrm{Fe}(\mathrm{CN})_{6}\right]$ in $0.1 \mathrm{~mol} \mathrm{~L}^{-1} \mathrm{KCl}$ solution at $v=50 \mathrm{mV} \mathrm{s}^{-1}$. As can be observed in the inset of Figure $2 \mathrm{~A}$, the potential value did not change in the cyclic voltammograms using a different reference electrode, demonstrating the high stability of the proposed pseudo-reference electrode in maintaining a constant potential. 


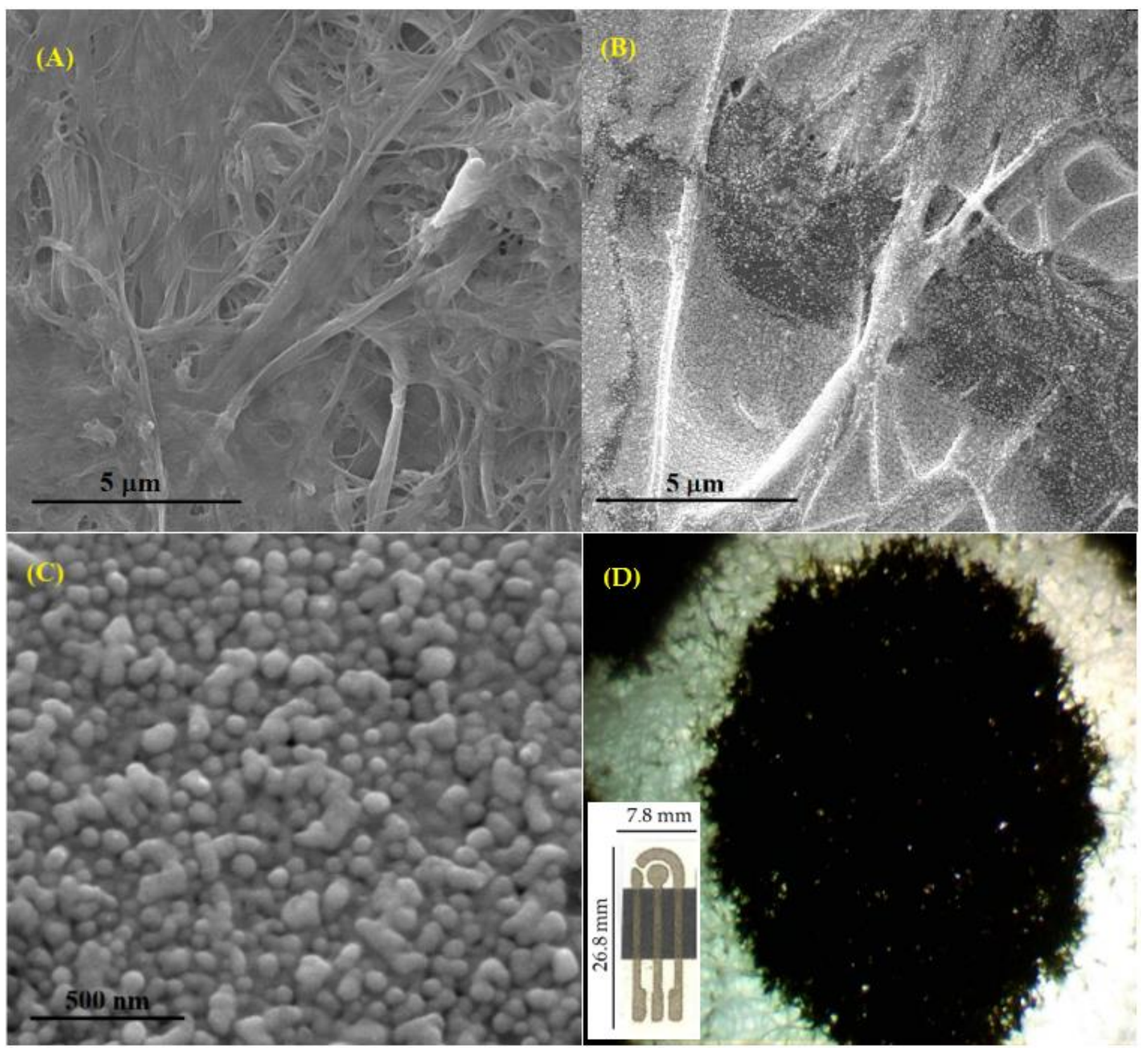

Figure 1. SEM images obtained from the (A) bare paper and $(\mathbf{B}, \mathbf{C})$ silver electrode surface printed on the paper substrate at different magnifications. Optical image (D) of the silver electrode. The inset is the photo of the three-electrode system.

The effectiveness of the paper-based silver three-electrode system (inset in Figure 1B) was evaluated using the $\mathrm{CV}$ technique and a $\left[\mathrm{Ru}\left(\mathrm{NH}_{3}\right)_{6}\right] \mathrm{Cl}_{3}$ electrochemical probe. Figure $2 \mathrm{~B}$ shows the cyclic voltammograms obtained by varying the potential scanning rate $\left(10-500 \mathrm{mV} \mathrm{s}^{-1}\right)$ for a solution of $1.0 \mathrm{mmol} \mathrm{L}^{-1}\left[\mathrm{Ru}\left(\mathrm{NH}_{3}\right)_{6}\right] \mathrm{Cl}_{3}$ in $0.1 \mathrm{~mol} \mathrm{~L}^{-1}$ phosphate buffer $\mathrm{pH} 7.0$, as well as the currents of the anodic peak $\left(I_{\mathrm{pa}}\right)$ and cathodic peak $\left(I_{\mathrm{pc}}\right)$ plots as a function of the square root of the scan rate (inset). It can be observed that both $\left(I_{\mathrm{pa}}\right.$ and $I_{\mathrm{pc}}$ ) vary linearly with the square root of the scan rate, indicating that the process was fully controlled by the diffusion of the electroactive species. The diffusion of the species was also confirmed by the $\log I$ vs. $\log v$ plot, which presented an angular coefficient of 0.6. This value is close of the theoretical reported value of 0.5 for diffusion-controlled processes [32]. From the results obtained in this study, the electroactive area for the proposed sensors was calculated by employing the Randles-Sevcik equation [33]. For $\left[\mathrm{Ru}\left(\mathrm{NH}_{3}\right)_{6}\right] \mathrm{Cl}_{3}$, $\mathrm{D}=9.78 \times 10^{-6} \mathrm{~cm}^{2} \mathrm{~s}^{-1}[34], n=1$, and $\mathrm{C}=1.0 \times 10^{-6} \mathrm{~mol} \mathrm{~cm}^{-3}$, the obtained elec- 
troactive area value $\left(1.58 \mathrm{~cm}^{2}\right)$ was almost 20 times bigger than the geometric area of $0.080 \pm 0.001 \mathrm{~cm}^{2}$. This response suggests that the silver electrode surface is highly porous, in agreement with SEM images (Figure 1). This property results in a higher analytical signal, demonstrating the potential of this electrode for analytical applications.
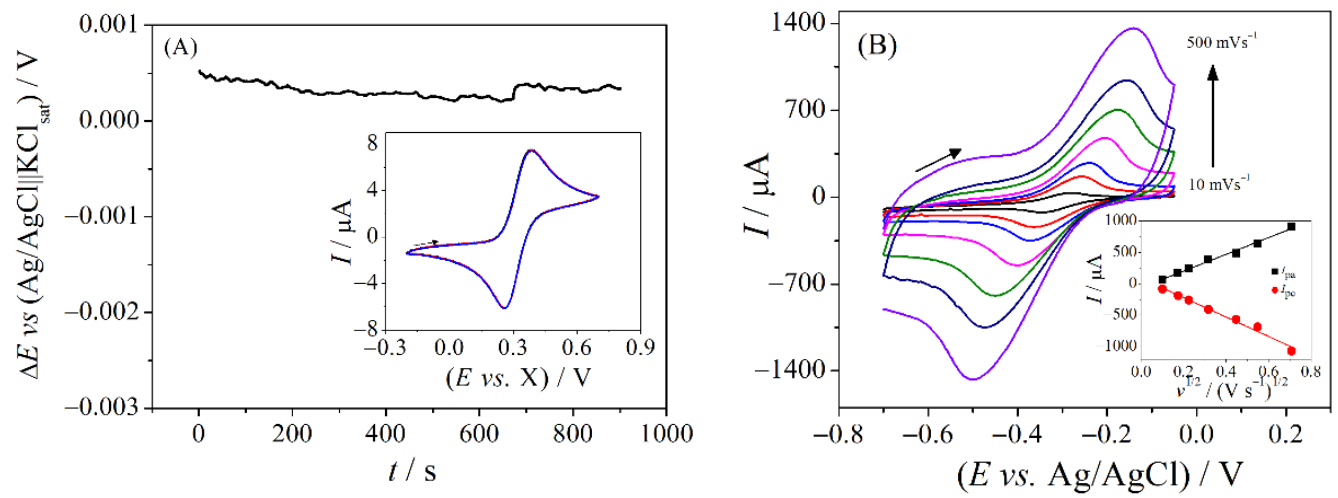

Figure 2. (A) Chronopotentiometric analysis comparing the behavior of the $\mathrm{Ag} / \mathrm{AgCl}$ pseudoreference electrode inkjet-printed on paper against a commercial $\mathrm{Ag} / \mathrm{AgCl}$ (saturated $\mathrm{KCl}$ solution). The insets are cyclic voltammograms obtained using a glassy carbon electrode and the pseudoreference electrode (duplicate) or commercial $\mathrm{Ag} / \mathrm{AgCl}$ in the presence of $1.0 \mathrm{mmol} \mathrm{L}^{-1} \mathrm{~K}_{3}\left[\mathrm{Fe}(\mathrm{CN})_{6}\right]$ in $0.1 \mathrm{~mol} \mathrm{~L}^{-1} \mathrm{KCl}$ solution. (B) Cyclic voltammograms obtained using the paper-based silver sensor at different potential scanning rates $\left(10-500 \mathrm{mVs}^{-1}\right)$ in the presence of $1.0 \mathrm{mmol} \mathrm{L}{ }^{-1}\left[\mathrm{Ru}\left(\mathrm{NH}_{3}\right)_{6}\right] \mathrm{Cl}_{3}$ in $0.1 \mathrm{~mol} \mathrm{~L}^{-1}$ phosphate buffer $\mathrm{pH}$ 7.0. The inset graph shows the linear relationship of the anodic and cathodic peak currents as a function of the square root of the potential scan rate.

The heterogeneous electron transfer constant $\left(k^{0}\right)$ was also estimated from the same cyclic voltammetry data at different scan rates by applying the Nicholson method (for quasi-reversible systems controlled by diffusion) [35]. In this method, the value of $k^{0}$ is obtained using following equation:

$$
\psi=k^{0}\left[\frac{\pi D n v F}{R T}\right]^{-1 / 2}
$$

where $\psi$ is the kinetic parameter, $D=9.78 \times 10^{-6} \mathrm{~cm}^{2} \mathrm{~s}^{-1}, n=1, F$ is the Faraday's constant $\left(96,485 \mathrm{C} \mathrm{mol}^{-1}\right), R=8.314 \mathrm{~J} \mathrm{~K}^{-1} \mathrm{~mol}^{-1}$, and $T=298.15 \mathrm{~K}$. The $\psi$ values were calculated from the $\Delta \mathrm{Ep}$ values verified at each scan rate using an empirical equation proposed by Lavagnini et al. [36]:

$$
\psi=\frac{(-0.6288+0.0021 n \Delta E p)}{(1-0.017 n \Delta E p)}
$$

From the calculated $\psi$ values, the $k^{0}$ value for the $\left[\mathrm{Ru}\left(\mathrm{NH}_{3}\right)_{6}\right] \mathrm{Cl}_{3}$ redox reaction was determined to be $0.0040 \mathrm{~cm} \mathrm{~s}^{-1}$. The value is better than or comparable to the same parameter obtained using a paper graphitic SPE electrode $\left(0.0012 \mathrm{~cm} \mathrm{~s}^{-1}\right)$ [37] and $\left(0.00072 \mathrm{~cm} \mathrm{~s}^{-1}\right)$ [38] and a platinum nanoparticle-decorated vertically aligned graphene SPE electrode $\left(0.0041 \mathrm{~cm} \mathrm{~s}^{-1}\right)$ [39].

\subsection{Electrochemical Behavior of Paraquat Pesticide}

Cyclic voltammograms of samples with and without paraquat were recorded in $0.1 \mathrm{~mol} \mathrm{~L}^{-1} \mathrm{Na}_{2} \mathrm{SO}_{4}$ solution ( $\mathrm{pH} 7.0$ ) to evaluate its electrochemical behavior using the developed sensor. The $\mathrm{Na}_{2} \mathrm{SO}_{4}$ solution was chosen as the supporting electrolyte because it has previously led to good responses for this analyte, as demonstrated in other works [21,40-42].

As shown in Figure 3, in the absence of paraquat (black dashed line voltammogram), no faradaic process was observed, corresponding to the response of the bare electrode related to the intrinsic structure and surface of the sensor; when adding paraquat, two 
quasi-reversible cathodic peaks at $-0.38 \mathrm{~V}$ and at $-0.86 \mathrm{~V}$ and two overlapping (as seen by the peak distortion) anodic peaks around $-0.68 \mathrm{~V}$ (vs. $\mathrm{Ag} / \mathrm{AgCl}$ ) were observed. According to the literature data, the first one is related to the reversible electrochemical reduction involving the formation of the radical $\mathrm{PQ}^{\bullet+}$ cation (Equation (1)), while the second one is related to the reduction of this generated species, forming the neutral molecule $\mathrm{PQ}^{0}$ (Equation (2)) [28,43]. Coproportionation can also occur between $\mathrm{PQ}^{0}$ and $\mathrm{PQ}^{2+}$ to generate two $\mathrm{PQ}^{\bullet+}$. The reduction scheme may be represented by the following equations:

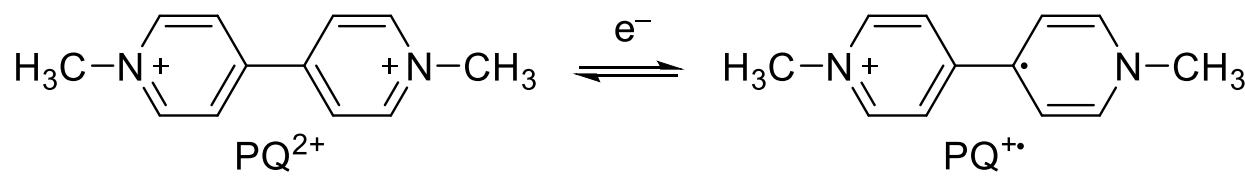<smiles>CN1C=CC(=C2C=CN(C)C=C2)C=C1</smiles>

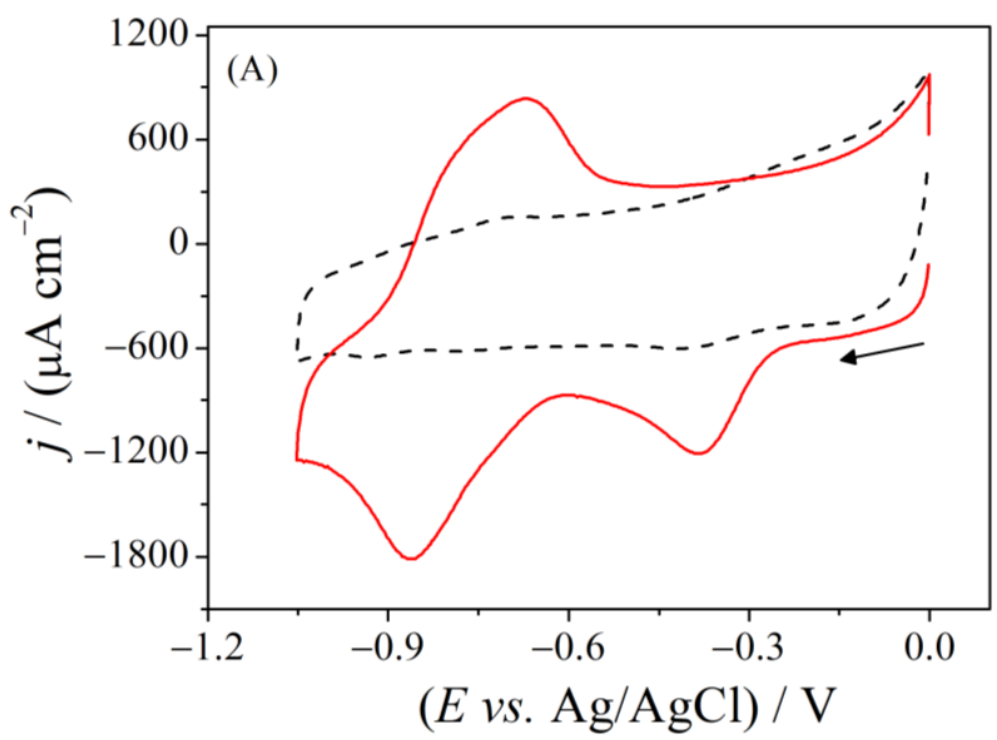

Figure 3. Cyclic voltammograms obtained using a paper-based silver sensor in the absence (black dashed line) and in the presence (red solid line) of $1.0 \mathrm{mmol} \mathrm{L}^{-1}$ paraquat in $0.1 \mathrm{~mol} \mathrm{~L}^{-1} \mathrm{Na}_{2} \mathrm{SO}_{4}$, $v=100 \mathrm{mV} \mathrm{s}^{-1}$.

The oxidation process at $-0.68 \mathrm{~V}$ was used for further study because, at this potential, higher detectability was achieved in comparison to that obtained in the two cathodic processes.

\subsection{Determination of Paraquat Using SWV}

Preliminary studies on the effect of SWV parameters on the redox process of paraquat were evaluated in the conditions presented in Table 1. The best electrochemical response was selected from the obtained voltammograms with low background noise and a well-defined and high-intensity peak for paraquat, as can be inferred from the data in Figures S1-S3 in Supplementary Materials. 
Table 1. Optimization of experimental conditions for paraquat detection using the square-wave voltammetry (SWV) technique.

\begin{tabular}{ccc}
\hline Parameter & Evaluated Conditions & Best Conditions \\
\hline SWV frequency $(f)$ & $3-10 \mathrm{~Hz}$ & $3 \mathrm{~Hz}$ \\
\hline SWV amplitude $(a)$ & $10-70 \mathrm{mV}$ & $60 \mathrm{mV}$ \\
\hline SWV potential increment $(\Delta E)$ & $1-5 \mathrm{mV}$ & $2 \mathrm{mV}$ \\
\hline
\end{tabular}

Next, square-wave voltammograms were registered under optimized conditions for varied concentrations of paraquat in $0.1 \mathrm{~mol} \mathrm{~L}^{-1} \mathrm{Na}_{2} \mathrm{SO}_{4}$ in order to build the analytical curve. The obtained graphs are presented in Figure 4. The analytical curve for paraquat (Figure $4 \mathrm{~B}$ ) is linear in the range from 3.0 to $100 \mu \mathrm{mol} \mathrm{L}^{-1}$, with a linear corre-

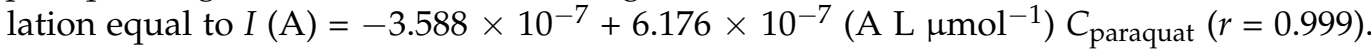
The LOD and LOQ values (calculated as described in the experimental procedure) were $0.80 \mu \mathrm{mol} \mathrm{L}{ }^{-1}$ and $2.5 \mu \mathrm{mol} \mathrm{L}{ }^{-1}$, respectively. Although the achieved LOD is not the best in comparison with those reported in previous studies (Table 2), it is better than some [44,45], and compared with others [23,46], it is clearly acceptable. It is also worth mentioning that while some sensors showed lower detection limits, their linear range was narrower than that of the proposed sensor. The printed sensor also has the great advantage of being produced without further modification steps when compared to all other chemically modified electrodes and is a potential platform for sustainable and disposable monitoring devices.

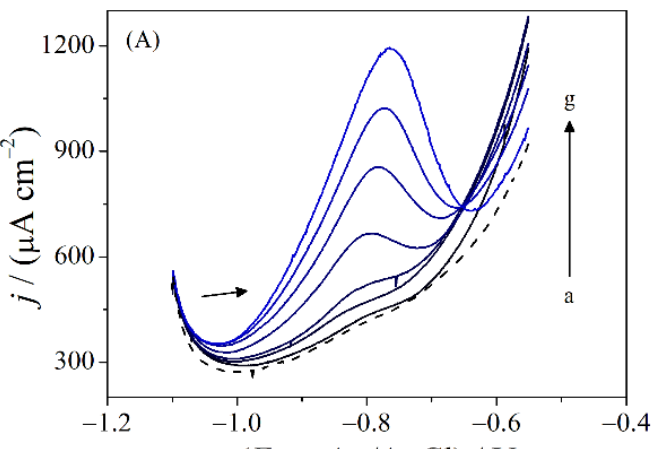

(Evs. $\mathrm{Ag} / \mathrm{AgCl}) / \mathrm{V}$

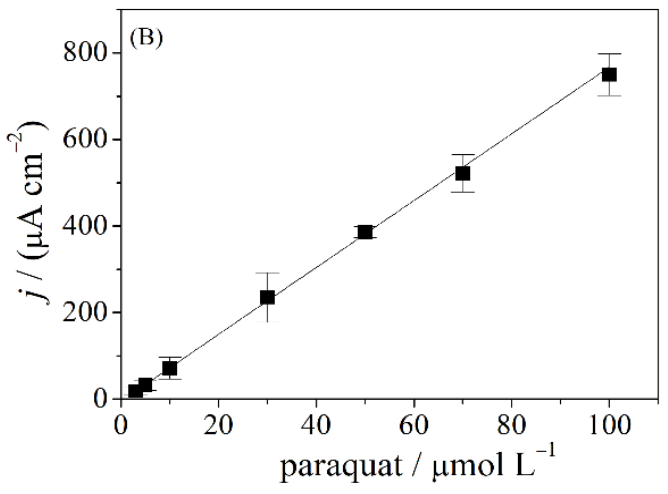

Figure 4. (A) Square-wave voltammograms obtained using the paper-based silver sensor in the absence (dashed line) and presence of different concentrations of paraquat (solid line: (a) $3.0 \mu \mathrm{mol} \mathrm{L}{ }^{-1}$, (b) $5.0 \mu \mathrm{mol} \mathrm{L}-1$, (c) $10.0 \mu \mathrm{mol} \mathrm{L}-1$, (d) $30.0 \mu \mathrm{mol} \mathrm{L}-1$, (e) $50.0 \mu \mathrm{mol} \mathrm{L}^{-1}$, (f) $70.0 \mu \mathrm{mol} \mathrm{L}-1$, and (g) $100 \mu \mathrm{mol} \mathrm{L}-1)$ ) in $0.1 \mathrm{~mol} \mathrm{~L}^{-1} \mathrm{Na}_{2} \mathrm{SO}_{4}$ solution. (B) The respective analytical curve. SWV conditions: $f=3 \mathrm{~Hz} ; a=60 \mathrm{mV} ; \Delta E=2 \mathrm{mV}$.

\subsection{Repeatability, Selectivity, and Sample Analysis}

To assess the fabrication repeatability of the proposed sensor, inter-electrode measurements were performed on the same day with five different sensors $(n=5)$. This study was carried out for two concentration of paraquat $\left(10.0 \mu \mathrm{mol} \mathrm{L}^{-1}\right.$ and $\left.70.0 \mu \mathrm{mol} \mathrm{L}{ }^{-1}\right)$ in a $0.1 \mathrm{~mol} \mathrm{~L}^{-1} \mathrm{Na}_{2} \mathrm{SO}_{4}$ solution, as seen in Figure 5. The relative standard deviation (RSD) values obtained were $7.1 \%$ and $4.1 \%$, respectively, indicating the high repeatability of the sensor fabrication method. This behavior is due to the simplicity and automatization of the procedure adopted for the fabrication of electrochemical sensors. 
Table 2. Comparison of the performance of different chemically modified electrodes for the detection of paraquat (PQ).

\begin{tabular}{|c|c|c|c|c|}
\hline Electrode & $\begin{array}{c}\text { Linear Range } \\
(\mu \mathrm{mol} \mathrm{L}-1)\end{array}$ & $\left.\operatorname{LOD}(\mu \mathrm{mol} \mathrm{L})^{-1}\right)$ & Technique & Reference \\
\hline CB-alginate film/GCE & $1.6-7.8$ & 0.23 & SWV & [23] \\
\hline AgNP/MWCNT/Nafion/GCE & $0.10-10$ & 0.07 & AsDPV & [24] \\
\hline $\mathrm{BN} / \mathrm{MoS}_{2} / \mathrm{AuNPs} / \mathrm{GCE}$ & $0.10-100$ & 0.07 & DPV & [25] \\
\hline HMDE & $0.25-1.7$ & 0.04 & DPCSV & [27] \\
\hline $\mathrm{Bi} / \mathrm{SPM}$ & $0.12-4.2$ & 0.01 & DPV & [28] \\
\hline CNT-Nafion/SPE & $0.54-4.3$ & 0.02 & SI-DPV & [29] \\
\hline AuNPs/DNA/GCE & $5.0-3000$ & 1.3 & DPV & [44] \\
\hline GCE & $3.9-31.0$ & 3.2 & SWV & [45] \\
\hline $\begin{array}{c}\mathrm{Cu}_{2} \mathrm{O} / \mathrm{PVP}-\mathrm{GNs} / \mathrm{GC}- \\
\mathrm{RDE}\end{array}$ & $1.0-200$ & 0.26 & DPV & [46] \\
\hline Paper-based silver sensor & $3.0-100$ & 0.80 & SWV & This work \\
\hline
\end{tabular}

$\overline{\mathrm{CB}}$ = carbon black; GCE = glassy carbon electrode; AgNP = silver nanoparticles; MWCNT = multiwall carbon nanotubes; AsDPVs = adsorptive differential pulse voltammetry; $\mathrm{BN}=$ boron nitride; $\mathrm{AuNPs}=$ gold nanoparticles $\mathrm{HMDE}=$ hanging mercury drop electrode; DPCSV = differential pulse cathodic stripping voltammetry; Bi/SPM = bismuth film screen-printed mini sensor; $\mathrm{CNT}$ = carbon nanotubes; SPE = screen-printed electrode; SI-DPV = sequential injection differential pulse voltammetry; PVP-GNs: polyvinyl pyrrolidone functionalized graphene nanosheets; GC-RDE: glassy carbon-rotating disk electrode.

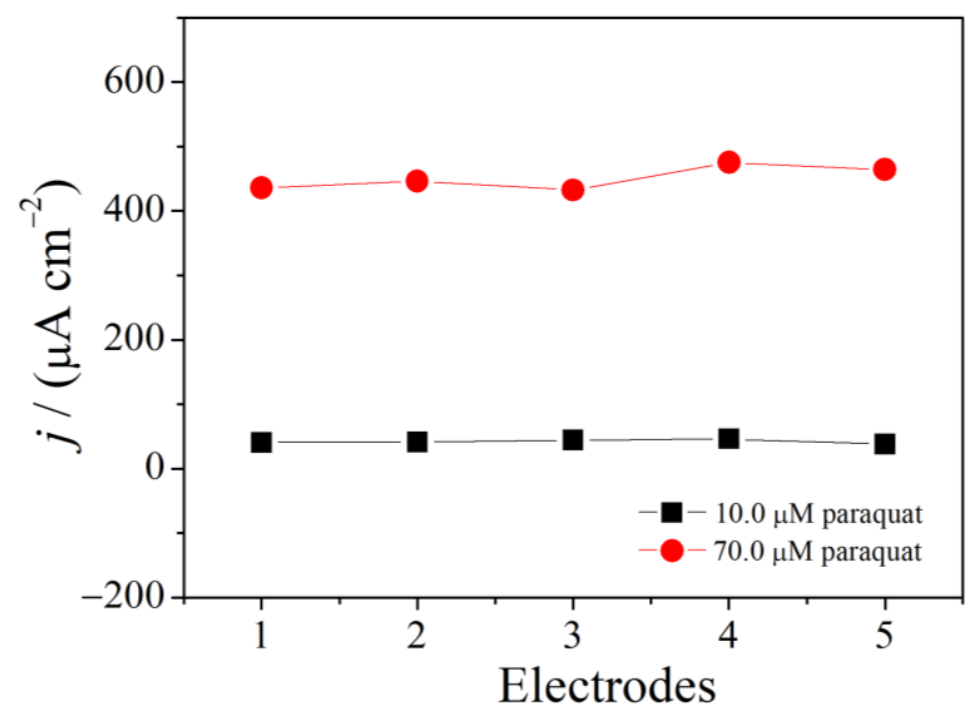

Figure 5. Analytical signal obtained in the inter-electrode repeatability study for the determination of paraquat (at two different concentrations) in $0.1 \mathrm{~mol} \mathrm{~L}^{-1} \mathrm{Na}_{2} \mathrm{SO}_{4}$ solution using SWV and the proposed paper-based silver sensor.

The selectivity of the printed sensor was evaluated in an interference study (Figure 6), where a $50.0 \mu \mathrm{mol} \mathrm{L}{ }^{-1}$ paraquat solution was analyzed in the absence and in the presence of different chemical species (glucose, albumin, ascorbic acid, and different metal cations) that were considered as possible interferents at a concentration ratio of 1/10 (analyte/interferent). The measurements were made in triplicate $(n=3)$, and the error bars correspond to the relative standard deviation between them. 


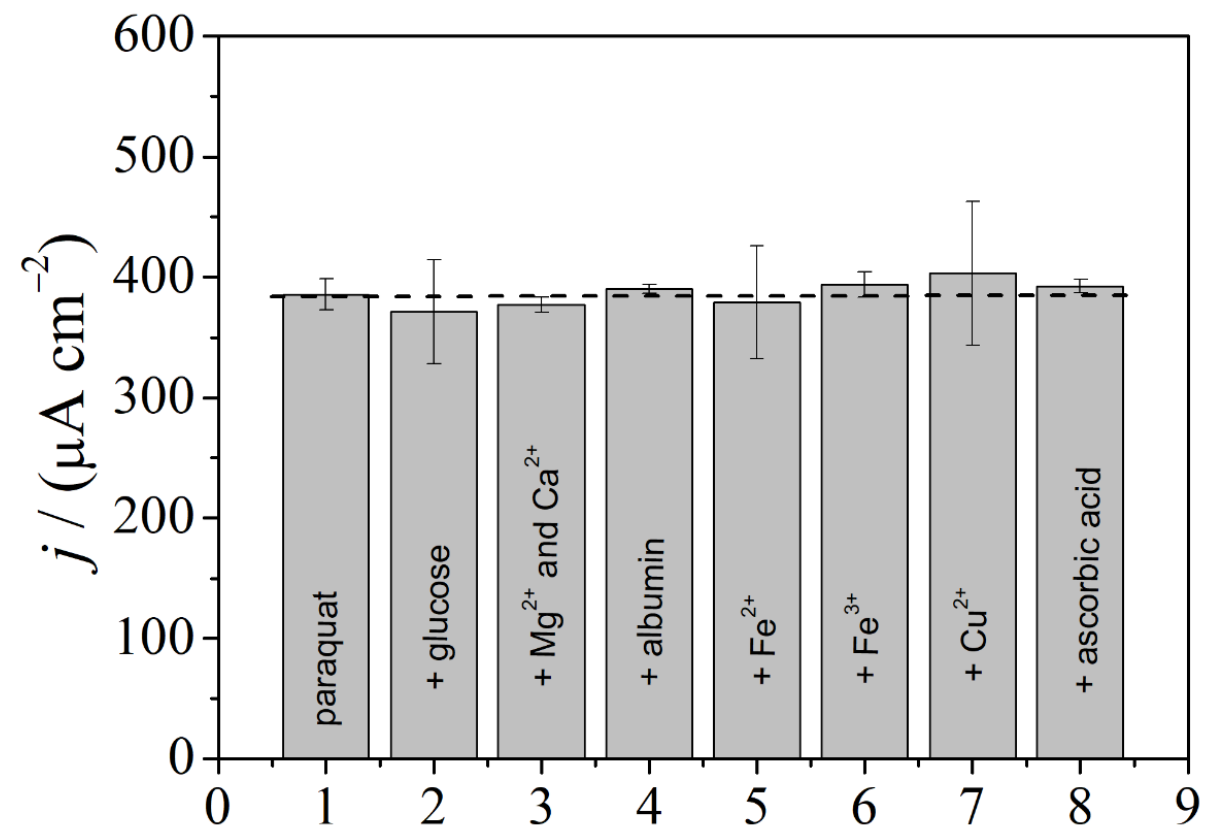

Figure 6. Effect of possible interferents on the SWV determination of a $50.0 \mu \mathrm{mol} \mathrm{L}{ }^{-1}$ paraquat solution at $1 / 10$ concentration ratios (analyte/interferent) in $0.1 \mathrm{~mol} \mathrm{~L}^{-1} \mathrm{Na}_{2} \mathrm{SO}_{4}$ solution using the paper-based silver sensor.

As shown in Figure 6, the signals recorded with the addition of interfering species remained practically constant in comparison with the paraquat oxidation signal obtained in the absence of these investigated interferents (the voltammograms obtained can be seen in Figure S5 in Supplementary Materials). Thus, it is possible to conclude that paraquat can be determined selectively with the proposed electroanalytical method in the presence of these possible investigated interferents.

The performance of the herein described new inkjet-printed sensor for the detection of paraquat was applied for its quantification in different complex matrices, such as human blood serum, food, and drinking water. These samples were prepared as described in Section 2.1 and fortified with a paraquat standard solution in order to obtain a solution concentration of $30.0 \mu \mathrm{mol} \mathrm{L}{ }^{-1}$. The determination of the pesticide was performed by interpolating the obtained current value in the previously obtained analytical curve. The voltammograms obtained for each sample can be seen in Figure S6 in Supplementary Materials. By analyzing the results presented in Table 3, it is possible to see that the recoveries ranged from $97 \%$ to $113 \%$. Thus, we can infer that paraquat can be successfully determined in different complex matrices by the herein reported printed sensor since there were no significant matrix interferences.

Table 3. Results obtained in the determination of paraquat in water, orange juice, and biological serum samples using the proposed method using the paper-based silver sensor.

\begin{tabular}{|c|c|c|c|}
\hline Sample & Added $\left(\mu \mathrm{mol} \mathrm{L} \mathrm{L}^{-1}\right)$ & Found $^{1}\left(\mu \mathrm{mol} \mathrm{L}{ }^{-1}\right)$ & Recovered \% \\
\hline Drinking water & 30.0 & $29 \pm 4$ & $97 \pm 12$ \\
\hline Orange juice & 30.0 & $30 \pm 1$ & $103 \pm 3$ \\
\hline Blood serum & 30.0 & $34 \pm 2$ & $113 \pm 6$ \\
\hline
\end{tabular}

\section{Conclusions}

Here, we prepared, characterized, and applied silver inkjet-printed electrodes on paper for the analytical determination of paraquat. The proposed device is cheap and easy to fabricate, and yet its analytical characteristics are comparable to other more complex sensors reported in the literature. 
The combination of inkjet-printing technology with a porous paper substrate allowed the electroactive area to be almost 20 times bigger than the geometric area, which resulted in a higher analytical signal; furthermore, a heterogeneous electron transfer constant that was better than or comparable to the same parameter was obtained using modified screen-printed electrodes.

Furthermore, the ink-jet printing technology adopted provided high precision and resolution with great reproducibility of the printed electrodes.

Thus, the simplicity of the proposed method combined with the reported results suggests its reliability and potential for use in routine analysis. The presented results also show the robustness of the method, which can be applied for a wide range of matrices with sufficient accuracy and precision with the advantages of being cost-effective and environmentally friendly.

Supplementary Materials: The following are available online at https:/ /www.mdpi.com/2227-904 0/9/4/61/s1, Figure S1: (A) Resistance of paper-based inkjet-printed electrode and (B) Cyclic voltammograms of silver electrode in $0.5 \mathrm{~mol} \mathrm{~L}^{-1} \mathrm{H}_{2} \mathrm{SO}_{4}$ solution as function of printed layers number, Figure S2: Square-wave voltammograms obtained as function of the square-wave frequency variation using the paper-based silver sensor in the presence of $100 \mu \mathrm{mol} \mathrm{L}^{-1}$ paraquat in $0.1 \mathrm{~mol} \mathrm{~L}^{-1} \mathrm{Na}_{2} \mathrm{SO}_{4}$ solution (pH 7.0). SWV conditions: $a=20 \mathrm{mV} ; \Delta E=5 \mathrm{mV}$, Figure S3: Square-wave voltammograms obtained as function of the pulse amplitude variation using the paper-based silver sensor in the presence of $100 \mu \mathrm{mol} \mathrm{L}-1$ paraquat in $0.1 \mathrm{~mol} \mathrm{~L}^{-1} \mathrm{Na}_{2} \mathrm{SO}_{4}$ solution ( $\mathrm{pH} 7.0$ ). SWV conditions: $f=3 \mathrm{~Hz} ; \Delta E=5 \mathrm{mV}$, Figure S4: Square-wave voltammograms obtained as function of the scan increment variation using the paper-based silver sensor in the presence of $100 \mu \mathrm{mol} \mathrm{L}^{-1}$ paraquat in $0.1 \mathrm{~mol} \mathrm{~L}^{-1} \mathrm{Na} 2 \mathrm{SO} 4$ solution (pH 7.0). SWV conditions: $f=3 \mathrm{~Hz} ; a=60 \mathrm{mV}$, Figure S5: Squarewave voltammograms obtained using the paper-based silver sensor for $50 \mu \mathrm{mol} \mathrm{L} \mathrm{L}^{-1}$ paraquat in $0.1 \mathrm{~mol} \mathrm{~L}^{-1} \mathrm{Na} 2 \mathrm{SO} 4$ solution ( $\mathrm{pH} 7.0$ ) in the presence of possible interferents. SWV conditions: $f=3 \mathrm{~Hz} ; a=60 \mathrm{mV} ; \Delta E=2 \mathrm{mV}$, Figure S6: Square-wave voltammograms obtained for the quantification of paraquat in different matrices using the paper-based silver sensor. Supporting electrolyte: $0.1 \mathrm{~mol} \mathrm{~L}^{-1} \mathrm{Na} 2 \mathrm{SO} 4$ solution (pH 7.0). SWV conditions: $f=3 \mathrm{~Hz} ; a=60 \mathrm{mV} ; \Delta E=2 \mathrm{mV}$.

Author Contributions: Conceptualization: P.B.D.; experimental investigation: P.B.D.; data analysis and interpretation: P.B.D. and D.W.J.; writing—original draft preparation: P.B.D.; writing-review and editing: D.W.J. and L.T.K.; supervision: L.T.K.; project administration: L.T.K.; funding acquisition: L.T.K. All authors have read and agreed to the published version of the manuscript.

Funding: This research was funded by São Paulo Research Foundation (FAPESP: grant 2013/221272 and grant 2019/00166), National Council for Scientific and Technological Development (CNPq: grant number 136386/2019-9), CAPES and National Institute of Science \& Technology in Bioanalytic (INCTBio).

Institutional Review Board Statement: Not applicable.

Informed Consent Statement: Not applicable.

Data Availability Statement: Not applicable.

Conflicts of Interest: The authors declare no conflict of interest. The funders had no role in the design of the study; in the collection, analyses, or interpretation of data; in the writing of the manuscript; or in the decision to publish the results.

\section{References}

1. Markets and Market. Available online: https://www.marketsandmarkets.com/Market-Reports/printed-electronics-market-197. html?gclid=Cj190KCQiA199P_BRC190ARIsAEZ196irgSR191SFZmKMO570OrbsHSYjrrqCmd105FyCtX-YJnXp192dGcQm193 xJ198sIaAv191sEALw_wcB (accessed on 15 January 2021).

2. Hayat, A.; Marty, J.L.J.S. Disposable screen printed electrochemical sensors: Tools for environmental monitoring. Sensors 2014, 14, 10432-10453. [CrossRef] [PubMed]

3. Honeychurch, K.C.; Hart, J.P. Screen-printed electrochemical sensors for monitoring metal pollutants. TrAC Trends Anal. Chem. 2003, 22, 456-469. [CrossRef]

4. Li, M.; Li, D.-W.; Xiu, G.; Long, Y.-T. Applications of screen-printed electrodes in current environmental analysis. Curr. Opin. Electrochem. 2017, 3, 137-143. [CrossRef] 
5. Thiyagarajan, N.; Chang, J.-L.; Senthilkumar, K.; Zen, J.-M. Disposable electrochemical sensors: A mini review. Electrochem. Commun. 2014, 38, 86-90. [CrossRef]

6. Hartwig, M.; Zichner, R.; Joseph, Y.J.C. Inkjet-printed wireless chemiresistive sensors-A review. Chemosensors 2018, 6, 66. [CrossRef]

7. Tortorich, R.P.; Shamkhalichenar, H.; Choi, J.-W.J.A.S. Inkjet-printed and paper-based electrochemical sensors. Appl. Sci. 2018, 8, 288. [CrossRef]

8. Paschoalino, W.J.; Kogikoski, S.K., Jr.; Barragan, J.T.C.; Giarola, J.F.; Cantelli, L.; Rabelo, T.M.; Pessanha, T.M.; Kubota, L.T. Emerging considerations for the future development of electrochemical paper-based analytical devices. ChemElectroChem 2019, 6, 10-30. [CrossRef]

9. Lee, V.B.C.; Mohd-Naim, N.F.; Tamiya, E.; Ahmed, M.U. Trends in paper-based electrochemical biosensors: From design to application. Anal. Sci. 2018, 34, 7-18. [CrossRef]

10. Deroco, P.B.; Giarola, J.D.F.; Wachholz Junior, D.; Lorga, G.A.; Kubota, L.T. Paper-based electrochemical sensing devices. Compr. Anal. Chem. 2020, 89, 91-137. [CrossRef]

11. Noviana, E.; McCord, C.P.; Clark, K.M.; Jang, I.; Henry, C.S. Electrochemical paper-based devices: Sensing approaches and progress toward practical applications. Lab a Chip 2020, 20, 9-34. [CrossRef]

12. Gonzalez-Macia, L.; Morrin, A.; Smyth, M.R.; Killard, A.J. Advanced printing and deposition methodologies for the fabrication of biosensors and biodevices. Analist 2010, 135, 845-867. [CrossRef] [PubMed]

13. Li, J.; Rossignol, F.; Macdonald, J. Inkjet printing for biosensor fabrication: Combining chemistry and technology for advanced manufacturing. Lab a Chip 2015, 15, 2538-2558. [CrossRef] [PubMed]

14. Liana, D.D.; Raguse, B.; Gooding, J.J.; Chow, E. Recent advances in paper-based sensors. Sensors 2012, 12, 11505-11526. [CrossRef]

15. Singh, A.T.; Lantigua, D.; Meka, A.; Taing, S.; Pandher, M.; Camci-Unal, G. Paper-based sensors: Emerging themes and applications. Sensors 2018, 18, 2838. [CrossRef] [PubMed]

16. Setti, L.; Fraleoni-Morgera, A.; Ballarin, B.; Filippini, A.; Frascaro, D.; Piana, C. An amperometric glucose biosensor prototype fabricated by thermal inkjet printing. Biosens. Bioelectron. 2005, 20, 2019-2026. [CrossRef] [PubMed]

17. Moya, A.; Sowade, E.; del Campo, F.J.; Mitra, K.Y.; Ramon, E.; Villa, R.; Baumann, R.R.; Gabriel, G. All-inkjet-printed dissolved oxygen sensors on flexible plastic substrates. Org. Electron. 2016, 39, 168-176. [CrossRef]

18. Cinti, S.; Arduini, F.; Moscone, D.; Palleschi, G.; Gonzalez-Macia, L.; Killard, A.J. Cholesterol biosensor based on inkjet-printed Prussian blue nanoparticle-modified screen-printed electrodes. Sens. Actuators B Chem. 2015, 221, 187-190. [CrossRef]

19. Sandström, J.; Broyer, A.; Zoia, D.; Schilt, C.; Greggio, C.; Fournier, M.; Do, K.Q.; Monnet-Tschudi, F. Potential mechanisms of development-dependent adverse effects of the herbicide paraquat in 3D rat brain cell cultures. NeuroToxicology 2017, 60, 116-124. [CrossRef]

20. Wesseling, C.; Joode, B.V.W.D.; Ruepert, C.; León, C.; Monge, P.; Hermosillo, H.; Partanen, L.J. Paraquat in developing countries. Int. J. Occup. Environ. Health 2001, 7, 275-286. [CrossRef] [PubMed]

21. Tomková, H.; Sokolová, R.; Opletal, T.; Kučerová, P.; Kučera, L.; Součková, J.; Skopalová, J.; Barták, P. Electrochemical sensor based on phospholipid modified glassy carbon electrode-Determination of paraquat. J. Electroanal. Chem. 2018, 821, 33-39. [CrossRef]

22. Tcheumi, H.L.; Tassontio, V.N.; Tonle, I.K.; Ngameni, E. Surface functionalization of smectite-type clay by facile polymerization of $\beta$-cyclodextrin using citric acid cross linker: Application as sensing material for the electrochemical determination of paraquat. Appl. Clay Sci. 2019, 173, 97-106. [CrossRef]

23. Pacheco, M.R.; Barbosa, S.C.; Quadrado, R.F.N.; Fajardo, A.R.; Dias, D. Glassy carbon electrode modified with carbon black and cross-linked alginate film: A new voltammetric electrode for paraquat determination. Anal. Bioanal. Chem. 2019, 411, 3269-3280. [CrossRef]

24. Ghalkhani, M.; Maghsoudi, S.; Saeedi, R.; Khaloo, S.S. Ultrasensitive quantification of paraquat using a newly developed sensor based on silver nanoparticle-decorated carbon nanotubes. J. Iran. Chem. Soc. 2019, 16, 1301-1309. [CrossRef]

25. Zhang, J.; Lin, Z.; Qin, Y.; Li, Y.; Liu, X.; Li, Q.; Huang, H. Fabricated Electrochemical Sensory Platform Based on the Boron Nitride Ternary Nanocomposite Film Electrode for Paraquat Detection. ACS Omega 2019, 4, 18398-18404. [CrossRef] [PubMed]

26. Souza, D.C.; Orzari, L.O.; de Oliveira, P.R.; Kalinke, C.; Bonacin, J.A.; Malaspina, O.; Nocelli, R.C.F.; Janegitz, B.C. Electro-chemical sensor based on beeswax and carbon black thin biofilms for determination of paraquat in Apis mellifera Honey. Food Anal. Methods 2020, 14, 606-615. [CrossRef]

27. Paramalinggam, T.; Yusoff, A.R.M.; Qureshi, M.S.; Shah, Z.A.; Sathishkumar, P.; Yusop, Z.; Khalid, M.; Khokhar, F.M. Determination of paraquat dichloride from water samples using differential pulse cathodic stripping voltammetry. Russ. J. Electrochem. 2018, 54, 1155-1163. [CrossRef]

28. De Figueiredo-Filho, L.C.; Baccarin, M.; Janegitz, B.C.; Fatibello-Filho, O. A disposable and inexpensive bismuth film minisensor for a voltammetric determination of diquat and paraquat pesticides in natural water samples. Sens. Actuators B Chem. 2017, 240, 749-756. [CrossRef]

29. Chuntib, P.; Themsirimongkon, S.; Saipanya, S.; Jakmunee, J. Sequential injection differential pulse voltammetric method based on screen printed carbon electrode modified with carbon nanotube/Nafion for sensitive determination of paraquat. Talanta 2017, 170, 1-8. [CrossRef] [PubMed] 
30. Da Silva, E.T.S.G.; Miserere, S.; Kubota, L.T.; Merkoçi, A. Simple on-plastic/paper inkjet-printed solid-state Ag/AgCl pseudoreference electrode. Anal. Chem. 2014, 86, 10531-10534. [CrossRef]

31. Mocak, J.; Bond, A.M.; Mitchell, S.; Scollary, G. A statistical overview of standard (IUPAC and ACS) and new procedures for determining the limits of detection and quantification: Application to voltammetric and stripping techniques (Technical Report). Pure Appl. Chem. 1997, 69, 297-328. [CrossRef]

32. Gosser, D.K. Cyclic Voltammetry: Simulation and Analysis of Reaction Mechanisms; VCH: New York, NY, USA, 1993 ; p. 165.

33. Bard, A.J.; Faulkner, L.R. Electrochemical Methods, Fundamentals and Applications, 2nd ed.; Wiley: New York, NY, USA, 2001.

34. Csóka, B.; Nagy, G. Determination of diffusion coefficient in gel and in aqueous solutions using scanning electrochemical microscopy. J. Biochem. Biophys. Methods 2004, 61, 57-67. [CrossRef]

35. Nicholson, R.S. Theory and application of cyclic voltammetry for measurement of electrode reaction kinetics. Anal. Chem. 1965, 37, 1351-1355. [CrossRef]

36. Lavagnini, I.; Antiochia, R.; Magno, F. An extended method for the practical evaluation of the standard rate constant from cyclic voltammetric data. Electroanalysis 2004, 16, 505-506. [CrossRef]

37. Foster, C.; Metters, J.P.; Kampouris, D.K.; Banks, C.E. Ultraflexible screen-printed graphitic electroanalytical sensing platforms. Electroanalysis 2014, 26, 262-274. [CrossRef]

38. Metters, J.P.; Kadara, R.O.; Banks, C.E. Fabrication of co-planar screen printed microband electrodes. Analist 2013, $138,2516-2521$. [CrossRef]

39. Scremin, J.; Dos Santos, I.V.J.; Hughes, J.P.; Ferrari, A.G.-M.; Valderrama, E.; Zheng, W.; Zhong, X.; Zhao, X.; Sartori, E.J.R.; Crapnell, R.D.; et al. Platinum nanoparticle decorated vertically aligned graphene screen-printed electrodes: Electrochemical characterisation and exploration towards the hydrogen evolution reaction. Nanoscale 2020, 12, 18214-18224. [CrossRef]

40. De Souza, D.; Machado, S.A.S. Study of the electrochemical behavior and sensitive detection of pesticides using microelectrodes allied to square-wave voltammetry. Electroanalysis 2006, 18, 862-872. [CrossRef]

41. El Harmoudi, H.; Achak, M.; Farahi, A.; Lahrich, S.; El Gaini, L.; Abdennouri, M.; Bouzidi, A.; Bakasse, M.; El Mhammedi, M. Sensitive determination of paraquat by square wave anodic stripping voltammetry with chitin modified carbon paste electrode. Talanta 2013, 115, 172-177. [CrossRef]

42. Farahi, A.; Achak, M.; El Gaini, L.; El Mhammedi, M.A.; Bakasse, M. Electrochemical determination of paraquat in citric fruit based on electrodeposition of silver particles onto carbon paste electrode. J. Food Drug Anal. 2015, 23, 463-471. [CrossRef]

43. Laghrib, F.; Bakasse, M.; Lahrich, S.; El Mhammedi, M. Electrochemical sensors for improved detection of paraquat in food samples: A review. Mater. Sci. Eng. C 2020, 107, 110349. [CrossRef] [PubMed]

44. Ribeiro, J.A.; Carreira, C.A.; Lee, H.J.; Silva, F.; Martins, A.; Pereira, C.M. Voltammetric determination of paraquat at DNA-gold nanoparticle composite electrodes. Electrochimica Acta 2010, 55, 7892-7896. [CrossRef]

45. Díaz, T.G.; Cabanillas, A.G.; Salinas, F. Square-Wave and differential pulse oxidative voltammetric determination of diquat and paraquat in alkaline medium. Electroanalysis 2000, 12, 616-621. [CrossRef]

46. Ye, X.; Gu, Y.; Wang, C. Fabrication of the $\mathrm{Cu} 2 \mathrm{O} /$ polyvinyl pyrrolidone-graphene modified glassy carbon-rotating disk electrode and its application for sensitive detection of herbicide paraquat. Sens. Actuators B Chem. 2012, 173, 530-539. [CrossRef] 